\title{
Os Estudos de Problemas Brasileiros na UERJ: a estrutura e as engrenagens de um projeto de socialização política
}

Samara Mancebo Lerner*

\begin{abstract}
Resumo
Analisa-se neste artigo a estrutura da pós-graduação em Estudo de Problemas Brasileiros criada por militares na Universidade do Estado do Rio de Janeiro, nos anos 70, durante a vigência do regime militar no Brasil. A análise dos documentos relativos à esta pós-graduação nos permite desvendar as engrenagens desse projeto de socialização política, demonstrando sua relação com a Escola Superior de Guerra e sua Doutrina de Segurança Nacional. Sustentase, neste artigo, que a pós-graduação em EPB foi criada com o objetivo de socializar os jovens na ideologia política do regime militar, justamente durante o período de abertura política, quando se mostrava importante garantir a transição para outro regime político, sem a tentação das ideologias do campo da esquerda.
\end{abstract}

\section{Palavras-chave}

Estudo de Problemas Brasileiros (EPB-UERJ). Escola Superior de Guerra (ESG). Socialização Política.

\begin{abstract}
In this article, it is analized the structure of a postgraduation course in Brazilian Problems Studies (EPB), created by the militaries in Rio de Janeiro State University (UERJ), in the 70s, during Brazilian Military Regime. The document analysis of this postgraduation course allows us to unveil the gears of such a political socialization project, demonstrating its relationship with the Superior School of War (ESG) and its National Security Doctrine (DSN). It is argued in this article that the postgraduation course in EPB was created with the intent of socializing young people in the Military Regime political ideology, precisely during the democratization
\end{abstract}

\footnotetext{
* Samara Mancebo Lerner é doutora em Ciências Sociais pela Universidade do Estado do Rio de Janeiro (UERJ) e professora de Sociologia do Departamento de Ciências Sociais da Pontifícia Universidade Católica do Rio de Janeiro (PUC-RJ). Atualmente, é pós-doutoranda no âmbito do Núcleo Interdisciplinar de Estudos sobre Desigualdades (NIED) da Universidade Federal do Rio de Janeiro (UFRJ). E-mail: samaramancebo@gmail.com.
} 
period, when it was important for the militaries, to keep leftist ideologies way from the Brazilian political scenario.

\section{Keywords}

Brazilian Problems Studies at Rio de Janeiro State University (EPB-UERJ). Superior School of War (ESG). Political Socialization.

\section{Apresentação}

Por cerca de duas décadas a Universidade do Estado do Rio de Janeiro e a Escola Superior de Guerra mantiveram intensa relação colaborativa. Desde sua criação, a Universidade buscou manter relações amistosas com os governos estadual e federal. Com a implantação do regime militar em 1964, esse quadro não foi modificado, e a UERJ manteve íntima relação de colaboração com os militares, contando, inclusive, com a participação de vários esguianos em seus órgãos superiores e unidades universitárias (MANCEBO, 1995; MANCEBO-LERNER, 2013). O estreitamento dessas relações garantiu prestigio à Universidade - frente aos militares - e permitiu à UERJ desenvolver um curso de Especialização e outro de Mestrado em Estudo de Problemas Brasileiros (EPB), sendo pioneira nessa área. Após análise da documentação pertinente à pós-graduação em EPB, observou-se que a mesma foi desenvolvida com base no programa de um curso elaborado dentro da Escola Superior de Guerra, fundamentado em sua Doutrina de Segurança Nacional, com o objetivo de socializar os jovens na ideologia política do regime militar.

Ao longo deste artigo, procuraremos remontar a estrutura dos Estudos de Problemas Brasileiros na UERJ - sob a forma de disciplina e de pós-graduação lato e stricto sensu - dando destaque aos propósitos para sua criação, às ideias e "projetos de nação", que buscavam disseminar e sua fundamentação doutrinária, visto que essas informações nos falam sobre o caráter políticoideológico dos EPB, bem como de sua função socializadora. A montagem das engrenagens que deram vida aos EPB na UERJ nos leva diretamente até a Escola Superior de Guerra (ESG) e sua Doutrina de Segurança Nacional (DSN). Este trabalho focará os Estudos de Problemas Brasileiros na Universidade do Estado do Rio de Janeiro, uma vez que a UERJ foi a única 
universidade, no Brasil, a desenvolver uma Pós-Graduação stricto sensu nessa área ${ }^{1}$.

Este artigo baseia-se na análise de fontes primárias relativas à disciplina de EPB, aos cursos de Especialização e Mestrado em EPB da UERJ, à Doutrina de Segurança Nacional e aos cursos desenvolvidos na ESG no início dos anos 70 .

\section{Sobre a disciplina de EPB e o contexto de sua criação}

Em 1969, no auge do regime autoritário, nasceu a disciplina de Estudo de Problemas Brasileiros como uma forma da Educação Moral e Cívica (EMC) no ensino superior. Seu currículo, assim como o da EMC, já nasceu comprometido com um projeto político-pedagógico bem definido, voltado para a socialização política em certa concepção de mundo fundamentada na Doutrina de Segurança Nacional e na tradição católica (BOMENY, 1981; CUNHA, 2007, 2010). Ficou estabelecido na legislação educacional do período que a EMC deveria ser ministrada sob a forma de disciplina e prática educativa, em todos os níveis e modalidades de ensino, devendo ainda assumir a forma de Estudo de Problemas Brasileiros no ensino superior. Deste modo, todas as instituições de ensino superior no Brasil, a partir de 1969, passaram a ministrar, compulsoriamente, a disciplina de EPB (DECRETO-LEI $\mathrm{n}^{\circ}$ 869/69; DECRETO CFE nํㅜ 68.065/71; PARECER CFE no 94/71).

A inclusão da disciplina de EPB no ensino superior ocorreu durante o Regime Militar e dentro de um contexto de agitação política por parte da juventude - organizada nos movimentos estudantis. Por sua participação ativa e de vanguarda ao longo dos anos 60, os estudantes tornaram-se um dos alvos prediletos do regime (HAYASHI; VICINO, 2007). À época, tornou-se comum o argumento - tanto em círculos militares quanto em civis que apoiavam o regime - de que as agitações de estudantes se ligavam, em especial, à aproximação dos jovens com a ideologia comunista e ao

\footnotetext{
${ }^{1}$ Este artigo baseia-se em pesquisa desenvolvida pela autora para realização de sua tese de doutorado, defendida pelo Programa de Pós-Graduação em Ciências Sociais da UERJ, em fevereiro de 2013 (MANCEBO-LERNER, 2013).
} 
suposto enfraquecimento dos valores morais que, por sua vez, apareciam como decorrentes da infiltração comunista. Na luta contra o comunismo e sua influência sobre a juventude, foram intensificados os mecanismos de repressão, transformada a legislação educacional (para aumentar o controle sobre a juventude) e criado um instrumento mais refinado para enfrentar a guerra revolucionária e psicológica que se apresentava ao regime dos militares (BORGES, 2009). Por instrumento estratégico, tomamos a disciplina de EPB. Além de disseminar em seu conteúdo um corpus de ideias voltadas para o fortalecimento de valores morais, ligados à tríade "Deus, Pátria, Família”, o EPB veiculava também a Doutrina de Segurança Nacional da ESG, socializando seus objetivos (ligados ao alcance do desenvolvimento e da segurança nacional), os problemas para o alcance desses objetivos, bem como os métodos para o equacionamento dos chamados problemas brasileiros. Junto à intenção de socializar os jovens na DSN, acreditava-se à época que, se envolvidos com o estudo dos problemas nacionais, os jovens não teriam tempo para desperdiçar energia com agitações políticas ${ }^{2}$. Um exemplo desse tipo de pensamento que predominou nos anos 60 pode ser observado em um Manifesto publicado na Folha de São Paulo, em novembro de 1965, e assinado pelo Movimento de Arregimentação Feminina. O Manifesto deixa transparecer o clima de guerra que dominava o imaginário social à época e a preocupação em torno da suscetibilidade da juventude frente ao comunismo, o que, por sua vez, legitimava a necessidade de submeter os jovens a uma formação moral e cívica durante percurso escolar:

Existe um campo de batalha onde nossos inimigos lutam com grande força e aparelhamento: é a mente de nossa mocidade, que alimentam com suas ideologias falsas. Enfrentemos essa luta no mesmo campo, com a bandeira da ideologia democrática, baseada nos princípios cristãos. (Folha de São Paulo, MAF, 1965 apud OLIVEIRA, 1982: 20).

Tornada obrigatória e tendo seu programa normatizado pelo Conselho Federal de Educação, a disciplina de EPB passou a integrar o currículo

\footnotetext{
${ }^{2}$ Este foi, inclusive, um dos argumentos que motivou a criação do Projeto Rondon em 1967. Não foi sem razão que, em 1973, a participação dos estudantes no Projeto Rondon foi considerada pelo Conselho Federal de Educação como créditos em Estudo de Problemas Brasileiros (PARECER CFE nº 1.293/73 apud BOLETIM UEG, Outubro de 1973, p. 907-910).
} 
dos cursos de graduação de todas as instituições de ensino superior no Brasil, dentre as quais a Universidade do Estado do Rio de Janeiro. Não obstante a obrigatoriedade da disciplina, muitas instituições resistiram à sua implementação, o que não ocorreu na UERJ - ao menos não de forma organizada ou contando com a adesão das autoridades da universidade. Respondendo a um jogo de múltiplos fatores e agentes e a uma permanente relação de colaboração entre civis e militares, de dentro e de fora da Universidade, a UERJ desenvolveu, logo que a legislação educacional determinou, um programa para a disciplina de EPB bastante fiel às determinações legais estabelecidas no Parecer no 94/71 do CFE (MANCEBOLERNER, 2013). Nesse Parecer, foram estabelecidas seis unidades, a partir das quais o ensino de EPB deveria ser desenvolvido:

\author{
Unidade I) Panorama Geral da Realidade Brasileira \\ Unidade II) Problemas Morfológicos \\ Unidade III) Problemas de Desenvolvimento Econômico \\ Unidade IV) Problemas Socioeconômicos \\ Unidade V) Problemas Políticos e \\ Unidade VI) Segurança Nacional (PARECER CFE n 9 94/71)
}

A UERJ adotou em sua grade curricular as mesmas unidades e seus respectivos conteúdos como diretrizes para o ensino da disciplina de EPB. Algumas universidades, como forma de resistir a esse ensino, tomando-o como imposição autoritária do regime militar, não adotaram todas as unidades e/ou não seguiram plenamente seus conteúdos. Esse não foi o caso da UERJ. Dentre as unidades mencionadas, duas delas, segundo Luiz Antonio Cunha (2012), "expressam, incontornavelmente, a doutrina da Escola Superior de Guerra”. O sociólogo se refere às unidades V e VI voltadas, respectivamente, para a discussão dos Problemas Políticos e da Segurança Nacional, cujos conteúdos envolvem temas como: O Poder Nacional: suas expressões; Segurança externa e interna - Responsabilidade do cidadão; Guerra Revolucionária; As Forças Armadas - Marinha, Exército e Aeronáutica; e Formulação de uma Doutrina e execução de uma política de segurança nacional - Conselho Nacional de Segurança - Estado Maior das Forças Armadas - Escola Superior de Guerra (PARECER CFE nº 94/71).

Em 1975, ano em que foi criada a Coordenação de Estudo de Problemas Brasileiros (CEPB) na UERJ, o programa de ensino de EPB foi reestruturado, passando a explicitar ainda mais, em seu conteúdo programático, um comprometimento ideológico com a DSN. O novo programa analítico da 
disciplina, reestruturado pelo coordenador de EPB - o general João Bina Machado $^{3}$-, passou a ser constituído de quatro unidades apenas:

\author{
Unidade I) Problemas do Desenvolvimento Políticos \\ Unidade II) Problemas de Desenvolvimento Econômico \\ Unidade III) Problemas do Desenvolvimento Social \\ Unidade IV) Problemas de Segurança Nacional (CEPB, Programa \\ da disciplina de EPB, UERJ, 1975)
}

Muito embora o programa de EPB criado pelo CFE já disseminasse a Doutrina de Segurança Nacional, como bem aponta Luiz Antônio Cunha, sua reestruturação na UERJ, em 1975, resultou em maior semelhança com a estrutura programática do Curso Superior de Guerra da ESG, na medida em que passou a organizar-se claramente a partir das quatro grandes áreas de concentração: política, econômica, (psico) social, e segurança nacional (militar). Depreende-se dessa constatação que, com a entrada do general Bina Machado na UERJ, as engrenagens construídas pelos militares para socialização política foram sendo cada vez mais aperfeiçoadas. Esse processo começou a arrefecer em meados da década de 80, mas só terminou ao final desta, com a extinção da disciplina de EPB da grade curricular da universidade.

\title{
A ESG, sua Doutrina, a fundamentação e o modelo para os Estudos de Problemas Brasileiros
}

Uma importante instituição foi criada dentro do campo militar, no final dos anos 40: a Escola Superior de Guerra. A ESG teve papel fundamental no processo de elaboração do conteúdo programático da EMC e, sobretudo, de EPB. Como aparelho de sustentação ideológica do campo militar e, posteriormente, do regime militar, a ESG não somente fortaleceu o referido campo e orientou as ações do Estado durante o regime, como se prontificou a criar instrumentos para disseminação de sua doutrina, dentre os quais o

\footnotetext{
${ }^{3}$ O General João Bina Machado foi comandante da ESG de 1972 a 1974. Um ano depois de deixar o comando da ESG, o general foi convidado para criar a CEPB e assumir sua coordenação.
} 
Estudo de Problemas Brasileiros.

A ESG foi criada pela Lei $n^{\circ} 785 / 49$ com o propósito de ser um centro misto de altos estudos militares e civis, com vistas a elaborar alternativas para equacionar os obstáculos ao desenvolvimento nacional. Os tempos de guerra fria que marcaram o nascimento da Escola deram a ela o inimigo que supostamente estaria "corroendo as bases políticas e sociais do país, o comunismo" e que, por isso, precisava ser combatido (SEPÚLVEDA, 2011, p.120). Pode-se dizer que a luta contra o comunismo motivou a construção de sua doutrina (DSN) e a formulação metodológico-doutrinária de seus cursos, dentre os quais o Curso Superior de Guerra (CSG), de onde proveio a estrutura da pós-graduação em EPB da UERJ.

A criação da Doutrina de Segurança Nacional, por sua vez, permitiu o desenvolvimento de "uma linguagem e ideias comuns com as quais se pensavam os problemas do país" (SANTOS, 2010, p. 100). A disseminação dessa linguagem e ideias imprimia uniformidade às propostas elaboradas dentro da Escola e evitava que as mesmas, prenhes de interesses do campo militar, fossem desviadas de seus propósitos originais. Sendo assim, todos os estagiários dos cursos da Escola eram socializados a partir de um mesmo referencial metodológico-doutrinário embasado na DSN, bem como direcionados a analisar e a buscar equacionar os problemas sociais a partir dele. A formação de profissionais civis e militares, segundo um mesmo referencial metodológico-doutrinário, e a participação de muitos esguianos no aparelho do Estado, mostraram-se estratégicos para a reprodução da ideologia política do regime e sua manutenção por cerca de duas décadas.

Quanto à Doutrina de Segurança Nacional, esta era, ao mesmo tempo, uma doutrina de ação política e a manifestação de uma ideologia que, por sua vez, repousava sobre as noções de guerra interna e permanente contra o comunismo. Nesse cenário de guerra, a doutrina caracterizava-se como anticomunista, antimarxista, cristã e democrática (BORGES, 2009; SANTOS, 2010). Motivada por esses valores e tendo seu foco sobre as questões da segurança e do desenvolvimento nacionais, a DSN desenvolveu-se a partir de quatro conceitos principais: Objetivos Nacionais, Poder Nacional, Estratégia Nacional e Segurança Nacional. O alcance e a manutenção dos Objetivos Nacionais representavam a função maior do Estado para a garantia da Segurança Nacional. Para alcançar os Objetivos Nacionais, o Estado deveria fazer uso do Poder Nacional, que funcionaria como um instrumento para o alcance daqueles objetivos. Constituíam os Objetivos Nacionais: integridade territorial, integração nacional, democracia, progresso, soberania e paz social 
(BORGES, 2009). Todos esses objetivos integram as finalidades dos cursos desenvolvidos na ESG, dentre os quais o Curso Superior de Guerra (CSG).

Desde o início de suas atividades, o CSG tem como público-alvo civis e militares e toma como objetivos estabelecer uma Doutrina de Segurança Nacional, formular uma Política de Segurança Nacional e, por fim, elaborar técnicas de planejamento para a Segurança Nacional (SVARTMAN, 2006). Nos anos 70, o Curso estruturava-se em três períodos de estudo, sendo o primeiro doutrinário, o segundo conjuntural e o terceiro, voltado para a aplicação dos conhecimentos assimilados nos períodos precedentes - o que significa a formulação da Política Nacional de Segurança e Desenvolvimento. As "disciplinas" dos cursos foram agrupadas dentro de cada um desses três períodos (ESG, D1-73; D2,74). O primeiro destinava-se a fornecer uma base conceitual ao estagiário, de modo que o mesmo pudesse refletir apropriadamente sobre os problemas conjunturais trabalhados no segundo período. Inicialmente, portanto, deveriam ser definidos os modos de pensar, a visão de mundo da Escola, que se fundamentava na DSN, para só então o estagiário ter condições de pensar sobre os problemas nacionais (e internacionais). De posse de métodos e conceitos doutrinários apropriados e do conhecimento acerca dos problemas sobre os quais importava refletir e solucionar, partia o estagiário para o terceiro período do curso, em que deveria demonstrar seus conhecimentos através da "formulação de planos, estratégias e políticas a serem aplicadas na sociedade" (SEPÚLVEDA, 2011, p. 154). Todos os temas desenvolvidos ao longo dos três períodos do CSG relacionavam-se às cinco unidades apresentadas a seguir:

\author{
Unidade I) Assuntos Políticos \\ Unidade II) Assuntos Econômicos \\ Unidade III) Assuntos Psicossociais \\ Unidade IV) Assuntos Militares \\ Unidade V) Generalidades (ESG, D4-123-72)
}

A organização do curso baseada nas referidas unidades demonstra claramente sua semelhança tanto com a estrutura programática da disciplina de EPB quanto com a estrutura da pós-graduação em EPB desenvolvida na UERJ, sobre a qual trataremos adiante. Antes disso, é preciso destacar que entre o Curso Superior de Guerra e a pós-graduação em EPB da UERJ está um projeto de curso de Mestrado, também em EPB, criado na ESG em 1973, sob a coordenação do então comandante da Escola, o general João Bina Machado. O referido projeto, apesar de aprovado pelo Conselho Federal 
de Educação em 1974, não chegou a ser desenvolvido na ESG, tendo-o sido, em verdade, na UERJ, poucos anos depois, quando Bina Machado já se encontrava reformado e responsável pela Coordenação de EPB nesta universidade. Como o curso de Mestrado não chegou a ser desenvolvido na Escola e sua estrutura e base doutrinária advinham do Curso Superior de Guerra, afirma-se que o CSG foi a fonte de onde se originou a pó-graduação em EPB da $\mathrm{UERJ}^{4}$.

O curso de Mestrado criado na ESG, tal qual o CSG, se estruturava a partir de quatro grandes áreas de concentração: política, econômica, psicossocial e militar, sendo esta última voltada apenas para militares. Suas disciplinas dividiam-se entre essas áreas e aquela chamada de área de domínio conexo, que compreendia a disciplina de Didática do Ensino Superior. O curso compartilhava com o CSG a mesma fundamentação metodológico-doutrinária de suas disciplinas/temas de trabalho, bem como os períodos a partir dos quais se estruturava - embora não fosse usada a mesma terminologia.

Quanto aos objetivos arrolados para o curso de Mestrado em EPB criado na ESG, apresentam-se:

a) Promover a formação, em nível de pós-graduação dos estagiários e formados do Curso Superior e do Curso de Estado-Maior e Comando das Forças Armadas.

b) Realizar a pesquisa e o desenvolvimento de estudos sistemáticos de alto nível nas áreas de concentração previstas neste regimento [a saber: política, econômica, psicossocial e militar].

c) Preparar especialistas, pesquisadores e professores em nível universitário para desempenhar funções de liderança e de superior hierarquia e responsabilidade no magistério e na administração do sistema escolar brasileiro, no que concerne ao Estudo de Problemas brasileiros. (Parecer CFE nº 1.331/74, p. 203).

Como recursos humanos, o Mestrado da ESG contou com um corpo permanente composto por oito professores (civis e militares com algum tipo de formação na ESG). Todos versavam "com igual proficiência as áreas

\footnotetext{
${ }^{4}$ A análise dos documentos de execução da ESG e do Parecer de Credenciamento do Mestrado em EPB da ESG (Parecer n ${ }^{\circ}$ 1331/74) nos fez concluir que a estrutura curricular e doutrinária do projeto do Mestrado em EPB proveio do Curso Superior de Guerra.
} 
política, econômica, psicossocial e militar" (PARECER CFE nำ 1.331/74), o que lhes permitia preparar "adequadamente" os futuros professores e coordenadores para atuarem no campo de EPB. Por adequadamente, leia-se o grau de comprometimento ideológico e metodológico com a doutrina da Escola. Três dos professores que integraram o corpo docente do Mestrado em EPB da ESG pertenceram também ao corpo docente da pós-graduação em EPB desenvolvida na UERJ. Além desses, ambos os cursos compartilharam também a coordenação do mesmo general.

\section{A pós-graduação em EPB na UERJ}

Em 1975, a UERJ criou a Coordenação de Estudo de Problemas Brasileiros (CEPB) e abrigou, a partir de então, dois cursos de pós-graduação em EPB, uma Especialização e um Mestrado, cujos objetivos e programas explicitavam, de modo claro, interesses do campo militar. Os referidos cursos visavam contribuir para a formação da elite intelectual brasileira (segundo moldes politico-ideológicos bem definidos); cuidar para que seus valores morais (cristãos) fossem conservados; colaborar para a formação de professores para atuarem no campo da EMC/EPB nas instituições de ensino brasileiras, conforme determinações do próprio Parecer CFE nº 94/71; e estreitar as relações de colaboração entre a UERJ e o governo federal ${ }^{5}$.

Em 1976, teve início o curso de Especialização em EPB, que atuou como nivelamento para o curso de Mestrado. Este recebeu sua primeira turma em 1977. Ambos permaneceram em atividade até o final dos anos 80. É interessante assinalar que a pós-graduação em EPB desenvolveu-se na UERJ durante o período de abertura política, quando os militares não somente preparavam sua saída do governo, mas também contavam com menor apoio dos segmentos civis da sociedade. Nesse momento, a socialização em sua ideologia política apresentava-se como uma garantia de que o retorno ao

\footnotetext{
${ }^{5} \mathrm{O}$ interesse da UERJ em construir seu campus e de se firmar como uma universidade autônoma - ainda que essa autonomia fosse buscada através da centralização administrativa e não pela densidade acadêmica - levou a universidade a procurar os militares e a compartilhar com eles, além dos valores e da visão de mudo, projetos específicos (como os EPB) e a formação de seus profissionais (MANCEBO, 1995; MANCEBO-LERNER, 2013).
} 
regime democrático-representativo ocorreria sem a tentação das ideologias do campo da esquerda.

A pós-graduação em EPB da UERJ nasceu sob a justificativa de atender a "demanda do mercado de docência em nível superior" de ensino, na área de Estudo de Problemas Brasileiros (CEPB-SR-2, UERJ). Não obstante o objetivo arrolado, pode-se afirmar que estava entre seus principais objetivos a socialização de jovens e adultos em determinadas concepções de mundo e "projetos de Nação" de interesse dos militares, então no governo.

Com relação aos objetivos inicialmente apresentados para a criação do Mestrado em EPB na UERJ, sua Coordenação informa que o curso apresentava "[...] o mesmo objetivo que o autorizado para a Escola Superior de Guerra, cabe[ndo] a proposição de analogia de tratamento" (CEPB-SR-2, UERJ). A CEPB se refere ao Curso de Mestrado em EPB criado na ESG e aprovado pelo CFE em 1974. Além disso, e de forma bastante objetiva, a Coordenação de EPB condiciona a criação do Mestrado em EPB da UERJ à existência do projeto de Mestrado criado dentro da Escola Superior de Guerra. A citação seguinte deixa entrever que tanto o curso de Especialização quanto a CEPB já foram criados com a intenção de receber o curso de Mestrado, funcionando a Especialização como um nivelamento para ingresso neste último.

O comandante da Escola Superior de Guerra, [em 1973], determinou a constituição de um Grupo de Trabalho a fim de estudar a viabilidade da criação na Escola Superior de Guerra, do Curso de Mestrado em Estudo de Problemas Brasileiros. Mandado o Processo ao Conselho Federal de Educação para Parecer, o Conselheiro Tarcísio Meirelles Padilha, exara brilhante Parecer em que coloca de forma nítida a caracterização deste tipo de Mestrado. Desmobilizado o Curso na Escola Superior de Guerra, após a saída do então comandante [João Bina Machado], a UERJ achou por bem convidá-lo para a Coordenação de Estudo de Problemas Brasileiros e auscultado o Magnífico Reitor foi dado início ao Curso de Nivelamento para o Mestrado em Estudo de Problemas Brasileiros (CEPB-SR-2).

A pós-graduação em EPB da UERJ estruturava-se a partir de quatro grandes áreas de concentração:

- Desenvolvimento Político

- Desenvolvimento Social

- Desenvolvimento Econômico 
As disciplinas da área de concentração recebiam esse nome porque pertenciam ao campo específico de conhecimento, que constituia o objeto de estudo do aluno nos referidos cursos de pós-graduação. Além dessas, o Curso contava também com as chamadas disciplinas da área de domínio conexo que, por sua vez, diziam respeito àquelas que envolviam conteúdo didático-pedagógico (Programa do Curso de Mestrado em EPB, 1977 apud PROCESSO nº 3602/84 da SR2-UERJ).

\begin{tabular}{|c|c|c|}
\hline \multicolumn{2}{|c|}{ Disciplinas da pós-graduação em EPB-UERJ / 1979} & Cursos \\
\hline \multirow{7}{*}{$\begin{array}{c}\text { Disciplinas } \\
\text { Didático- } \\
\text { Pedagógicas } \\
\text { (Domínio conexo) }\end{array}$} & 1. Currículo e Programas em EPB & \multirow{3}{*}{ Especialização } \\
\hline & 2. Didática de Ensino Superior & \\
\hline & 3. Tecnologia Educacional & \\
\hline & 4. Filosofia da Educação & \multirow{4}{*}{ Mestrado } \\
\hline & 5. Medidas da Educação & \\
\hline & 6. Estatística Educacional & \\
\hline & 7. Metodologia de Pesquisa Educacional & \\
\hline \multirow{8}{*}{$\begin{array}{c}\text { Disciplinas } \\
\text { de Conteúdo } \\
\text { Específico } \\
\text { (Área de } \\
\text { concentração) }\end{array}$} & 8. Desenvolvimento Político I & Especialização \\
\hline & 9. Desenvolvimento Político II & Mestrado \\
\hline & 10. Desenvolvimento Econômico I & Especialização \\
\hline & 11. Desenvolvimento Econômico II & Mestrado \\
\hline & 12. Desenvolvimento Social I & Especialização \\
\hline & 13. Desenvolvimento Social II & Mestrado \\
\hline & 14. Segurança Nacional I & Especialização \\
\hline & 15. Segurança Nacional II & Mestrado \\
\hline
\end{tabular}

Fonte: DELIBERAÇÃO n⿳ำ 43/79

A divisão das disciplinas em áreas de domínio conexo e área de concentração bem como a tônica dos conteúdos dos trabalhos em ambos os cursos as ligam diretamente ao curso de Mestrado em EPB da ESG - e ao

\footnotetext{
${ }^{6}$ No caso do curso da UERJ, a quarta área de concentração dos cursos da ESG, chamada de militar, foi substituída pela área de segurança nacional. No entanto, os temas trabalhados na área de Segurança Nacional continuaram afins à doutrina e integraram temas relacionados a assuntos militares.
} 
Curso Superior de Guerra. A análise das ementas das disciplinas da área de concentração da pós-graduação em EPB da UERJ, conjugada à análise da estrutura curricular do CSG da ESG, nos permite observar grande semelhança entres os temas trabalhados nos referidos cursos. Destacaremos a seguir alguns dos temas comuns a ambos os cursos e chamaremos a atenção para a relação de proximidade existente entre os "períodos" que organizavam o CSG e o curso de Mestrado em EPB da UERJ.

Como visto anteriormente, o CSG estruturava-se em três períodos: Doutrinário, Conjuntural e de Aplicação. Na fase dedicada à Doutrina Básica e à Metodologia ( $1^{\circ}$ período), o estagiário entrava em contato com temas relacionados à política nacional; ao poder nacional (e suas respectivas expressões do poder político, econômico, psicossocial e militar); a teorias do desenvolvimento nacional; modelos de desenvolvimento; políticas e estratégias de desenvolvimento e de segurança; teorias da segurança e dos conflitos contemporâneos; informações nacionais; mobilização nacional; e metodologia para o estabelecimento da política nacional. Podemos observar a presença de todos esses temas distribuídos nas quatro disciplinas da área de concentração do curso de Especialização em EPB: Desenvolvimento Político I, Econômico I, Social I e Segurança Nacional I. Funcionando a Especialização como nivelamento para o Mestrado, pode-se afirmar que as discussões realizadas no período doutrinário do CSG estavam presentes no curso de Mestrado, constituindo seu "primeiro período" de estudos - o de nivelamento.

De posse dos referidos conhecimentos metodológicos e doutrinários, o aluno do CSG entrava em contato com seu objeto de estudo - os principais problemas nacionais de segurança e desenvolvimento, chamados de conjunturais. Só então estava apto a aplicar seus conhecimentos e a elaborar uma Política Nacional de desenvolvimento e segurança para o Brasil. O processo de formação do Mestre em EPB na UERJ se dava, guardadas as devidas especificidades, de forma semelhante. Para ingressar no Mestrado, o aluno precisava ter concluído o curso de Especialização em EPB, uma primeira fase dos estudos em que tinha acesso a algumas disciplinas didáticopedagógicas e a outras da chamada área de concentração, que reuniam um conteúdo muito próximo daquele trabalhado no período doutrinário do CSG. Findado esse primeiro período, que pode também ser definido como de socialização em conhecimentos doutrinários "essenciais" para pensar os problemas brasileiros, o aluno era apresentado aos referidos óbices ao desenvolvimento e à segurança nacional. Este representava o "segundo 
período" de formação do curso, equivalente ao conjuntural do CSG, que no caso tinha início com o ingresso no curso de Mestrado em EPB e a realização das seguintes disciplinas da área de concentração: Desenvolvimento Político II, Econômico II, Social II e Segurança Nacional II.

O período dedicado à aplicação dos conhecimentos e métodos assimilados no decorrer da Especialização e do Mestrado ficava expresso na elaboração da dissertação de Mestrado, cujo tema vinculava-se, necessariamente, a um dos quatro campos/áreas de concentração do curso.

A análise das unidades didáticas do período conjuntural do CSC e das disciplinas do Mestrado em EPB da UERJ nos permite mapear os temas abordados em ambos os cursos, tomados como problemas brasileiros a serem conhecidos, interpretados e equacionados para o alcance do desenvolvimento e da segurança do país, dentre os quais podemos citar:

- Relações internacionais (do Brasil com os EUA e a Europa) e política externa

- Partidos e sistema político no Brasil

- Planejamento econômico brasileiro

- Problema energético brasileiro

- Integração nacional

- Ciência, tecnologia e desenvolvimento brasileiro

- Educação, saúde e desenvolvimento

- Segurança nacional

- Comunicação/informação no Brasil

- Comunismo/movimento comunista

- Políticas de estratégias e segurança nacional

- Conselho Nacional de Segurança

- Estado-Maior das Forças Armadas/EMFA

- Doutrina de Segurança Nacional (ESG, D4-123-72; ESG, D1-73, PROCESSO no 3602/84 da SR2-UERJ).

A fundamentação metodológico-doutrinária tanto do CSG quantos dos cursos de pós-graduação em EPB da UERJ assentava-se na Doutrina de Segurança Nacional, o que fica expresso claramente nos temas citados, trabalhados em ambos os cursos.

Outro fator que constitui as engrenagens do projeto criado pelos militares para socialização de sua ideologia política e que contribuiu para a semelhança estrutural entre os cursos da ESG e da UERJ diz respeito aos recursos humanos envolvidos com sua criação e desenvolvimento. Uma estrutura hábil para socializar a Doutrina de Segurança Nacional não poderia 
prescindir da participação de militares e civis formados pela ESG (e/ou afins à sua doutrina) na coordenação dos cursos de pós-graduação e em seu corpo docente. Além de Bina Machado, ex-comandante da ESG e coordenador da pós-graduação em EPB da UERJ, três desses oito professores do corpo permanente do Mestrado em EPB da Escola integraram o corpo docente da pós-graduação em EPB da UERJ: João de Alvarenga Soutto Mayor, Luiz Carlos Bastos Hosken e João Marinônio Aveiro Carneiro, tendo este último também assumido funções de coordenador da pós-graduação em EPB. Outros militares e civis com formação na ESG integraram o corpo docente e/ou assumiram funções na coordenação de EPB, dentre os quais estão o general Horácio Lemos Corrêa e o coronel Ítalo Costa Jóia.

\section{Considerações Finais}

Na contramão dos interesses dos militares, e apesar de toda a estrutura montada na UERJ, o desenvolvimento da pós-graduação em EPB, no decorrer dos anos 80, mostrou-nos que o projeto de socialização na ideologia política do regime militar, se não malogrou, teve vida mais curta do que a idealizada. $\mathrm{O}$ arrefecimento do Regime Militar e do poder de influência dos militares dentro da universidade associado a mudanças no cenário político estadual e na própria reitoria da UERJ culminaram em transformações também na estrutura da pós-graduação em EPB - o que incluiu modificação nos nomes das disciplinas e áreas de concentração. Apesar dessas modificações, o conteúdo disseminado através de ambos os cursos de EPB permaneceu reproduzindo temas, noções, ideias e projetos caros aos militares e contidos na Doutrina de Segurança Nacional. Esse processo só teve fim com a extinção dos Estudos de Problemas Brasileiros na UERJ, no final da década de $1980^{7}$.

Ao longo deste artigo, ainda que de forma breve, pudemos atestar a compatibilidade estrutural e ideológica "dos Estudos de Problemas Brasileiros" na UERJ com projetos e cursos desenvolvidos dentro da Escola Superior de Guerra. A referida compatibilidade mostrou-se expressa

\footnotetext{
${ }^{7}$ A disciplina de EPB foi formalnente extinta, na UERJ, em 1989, e os cursos de Especialização e Mestrado, em 1988. As atividades da pós-graduação seguiram até 1993, quando foi defendida a última dissertação de Mestrado pelo Programa de EPB da UERJ.
} 
não somente no conteúdo de uma disciplina obrigatória, como o foi EPB, mas na estrutura da pós-graduação em EPB, criada espontaneamente pela universidade, com a cuidadosa colaboração de militares esguianos. A identidade politico-ideológica encontrada entre a pós-graduação em EPB da UERJ e o CSG / Mestrado em EPB da ESG (expressa na convergência entre seus programas e na fundamentação doutrinária de seus cursos) permite-nos corroborar a tese de que os Estudos de Problemas Brasileiros foram criados com a função de socializar jovens e adultos na ideologia política do Regime Militar. Em outras palavras, pode-se dizer que a criação da pós-graduação em EPB foi concebida para disseminar, em meio civil e, especialmente, em campo legitimamente voltado para a produção de conhecimento, valores, ideias e projetos de Brasil que outrora haviam permitido a manutenção e a legitimidade do Regime Militar.

Partindo da premissa de que, em todos os tipos de regime, seus atores dominantes buscam disseminar sua ideologia política entre os atores relevantes do sistema, ou seja, procuram influenciar o processo de socialização política - como bem aponta Mário Brockmann Machado (1980) -, não estranha o esforço dos militares em criar instrumentos para reprodução de sua ideologia. Pode-se afirmar, no entanto, que o referido processo de socialização não logrou os resultados esperados pelos militares, apesar da robusta estrutura criada por eles e da grande sobrevida dessa estrutura nas instituições de ensino brasileiras. A rejeição generalizada aos Estudos de Problemas Brasileiros - no ensino superior e na pós-graduação -, tanto por alunos quanto por professores (que se recusavam a ministrar a disciplina de EPB em conformidade com o conteúdo determinado pelo CFE), em várias universidades Brasil afora, atesta senão o insucesso dessa experiência de socialização política, a não concretização de seus objetivos iniciais.

\section{Referências}

BOMENY, Helena Maria Bousquet.

(1981) Paraíso Tropical: a ideologia do civismo na

TVE do Maranhão. Rio de Janeiro: Achiamé.

BORGES, Nilson.

(2009) “A Doutrina de Segurança Nacional e os governos militares". In: Jorge Ferreira; Lucília Almeida Neves (Orgs.); 0 Brasil Republicano - O Tempo da Ditadura: regime militar e movimentos sociais em fins do século XX. Rio de Janeiro: Civilização Brasileira, Vol. 4, 30 Ed., p. 13-42.

CUNHA, Luiz Antônio.

(2010) Ambiguidade ideológica na universidade: os estudos de problemas brasileiros. Revista do Centro de Filosofia e Ciências Humanas/CFCH da UFRJ. Ano 1, v. 1, p. 10-33. 
(2012) Os estudos de Problemas Brasileiros na UFRJ: aproximações institucionais. Revista Contemporânea de Educação. Faculdade de Educação, UFRJ, Rio de Janeiro, v. 7, n.13, p. 193.

(2007). "Sintonia oscilante: religião, moral e civismo no Brasil - 1931/1997". Cadernos de Pesquisa (São Paulo), v. 37, n. 131, p. 285302.

HAYASHI, Maria Cristina Piumbato Innocentini; VICINO, Mariângela de Lello.

(2007) Movimento estudantil: história e memória do Centro Acadêmico Armando de Salles Oliveira (CAASO). Coleção Nova História. São Carlos: EDUFSCar.

MACHAD0, Mário Brockmann.

(1980) Ideologia, Socialização Política e Dominação. Dados, v. 2, p. 131-149.

MANCEBO, Deise.

(1995) Da gênese utilitária aos compromissos: uma história da Universidade do Estado do Rio de Janeiro (1950-1978). Tese apresentada ao Programa de Pós-graduação em Educação da Pontifícia Universidade Católica de São Paulo (PUC-SP). São Paulo.

MANCEBO-LERNER, Samara L. T.

(2013). A pós-graduação em Estudo de Problemas Brasileiros na UERJ: uma reflexão sociológica sobre um projeto de socialização política no Brasil. Tese de Doutorado apresentada ao Programa de Pós-graduação em Ciências Sociais da Universidade do Estado do Rio de Janeiro (UERJ). Rio de Janeiro.

OLIVEIRA, Maria Aparecida Brisolla.

(1982). Política e educação no Brasil: a implantação da obrigatoriedade da Educação Moral e Cívica no ensino brasileiro em 1969. Dissertação de mestrado apresentada ao Programa de Pós-graduação em Educação da Universidade de São Paulo. São Paulo.

SANTOS, Everton Rodrigo.

(2010) Poder e Dominação no Brasil: A Escola Superior de Guerra (1974-1989). Porto Alegre: Sulina; Novo Amburgo: Feevale.
SEPÚLVEDA, José Antônio Miranda.

(2011) O papel da Escola Superior de Guerra na projeção do campo militar sobre o campo educacional. Tese de doutorado apresentada na Universidade Federal do Rio de Janeiro. Rio de Janeiro.

SVARTMAN, Eduardo Munhoz.

(2006) Guardiões da nação. Formação profissional, experiências compartilhadas $e$ engajamento político dos generais de 1964. Tese de doutorado apresentada na Universidade Federal do Rio Grande do Sul. Porto Alegre.

\section{Documentos utilizados:}

CEPB. Coordenação de Estudo de Problemas Brasileiros, UERJ.

(1975) Programa analítico da disciplina de EPB, de 11 de agosto de 1975.

CEPB-SR-2. Coordenação de Estudo de Problemas Brasileiros-Sub-Reitoria de PósGraduação e Pesquisa, UERJ.

(Sem data) Pedido de Credenciamento do Curso de Mestrado em EPB, UERJ. Material enviado à Sub-Reitoria de Pós-Graduação e Pesquisa da UERJ, entre 1980 e março de 1983, para ser encaminhado à CAPES e ao CFE.

(12 de setembro de 1969). DECRETO-LEI no 869 do Conselho Federal de Educação, Brasil.

(14 de janeiro de 1971). DECRET0 no 68.065 do Conselho Federal de Educação, Brasil.

(21 de fevereiro 1979). DELIBERAÇÃO n० 43 do CSEP, UERJ (Conselho Superior de Ensino e Pesquisa da UERJ).

(1975) Dispõe sobre o Curso de Mestrado em EPB da UERJ.

ESG, D1-73.

(1973) Currículo dos Cursos. Departamento de Alunos.

ESG, D2-73.

(1973) Programa de Estudos (anexo C ao PGE/73). Departamento de Alunos. 
ESG, D2-74.

(1974) Plano Geral de Estudos Para o Ano Letivo de 1974. Departamento de Alunos.

ESG, D4-123-72.

(1972) Programa do $2 \circ$ Período do Ano Letivo de 1972. Departamento de Alunos, 1972.

ESG, Regulamento.

(1973).

(04 de fevereiro de 1971). PARECER no 94 do Conselho Federal de Educação, Brasil.

(09 de maio de 1974). PARECER no 1.331 do Conselho Federal de Educação, Brasil.

(1974) Credenciamento do Curso de PósGraduação - Nível de Mestrado - em Estudos Brasileiros.
PROCESSO no 3602 da SR-2 (Sub-Reitoria de Pós-Graduação e Pesquisa da UERJ).

(1984). Trata do processo de regulamentação do Curso de Mestrado em EPB da UERJ, aberto em 24 de setembro de 1984 e encerrado em 19 de outubro de 1987 pela Deliberação n 182 do CSEP, UERJ.

\section{Recebido em}

fevereiro de 2014

\section{Aprovado em}

julho de 2014 